\section{Fatal complication of gastric tear at diagnostic colonoscopy with deep sedation}

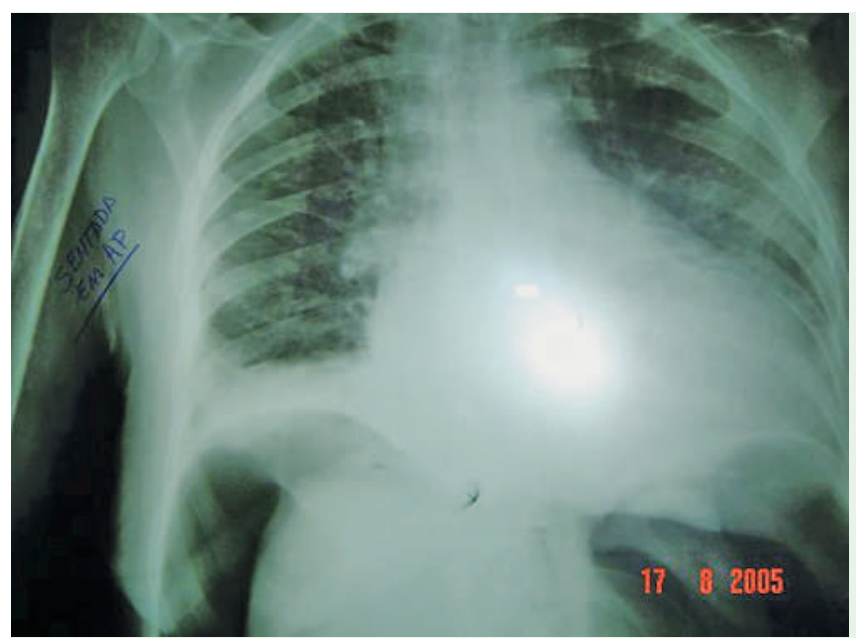

Figure 1 Pneumoperitoneum seen at radiology.

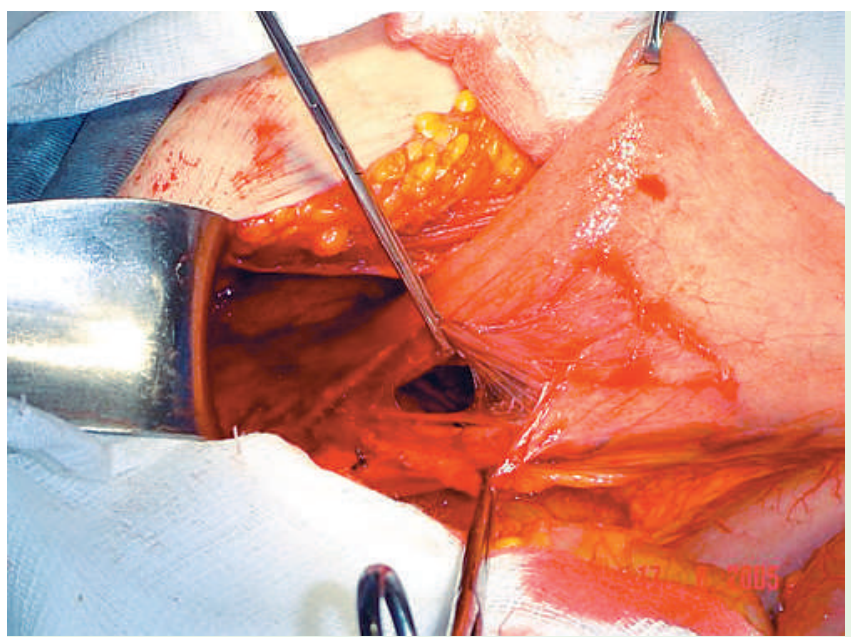

A 75-year-old woman presented for colonoscopy because of chronic abdominal pain. She also had coronary disease and hypertension.

Colonoscopy was carried out with the assistance of an anesthesiologist. After anesthesia with intravenous midazolam ( $2 \mathrm{mg}$ ) and propofol (40 mg) had been started, a nasopharyngeal catheter was inserted (oxygen flow rate, $4 \mathrm{~L} / \mathrm{min}$ ).

At the sigmoid colon, diverticula with no inflammatory signs were identified. At 2 minutes after anesthesia had been started, the patient was cyanosed and showed oxygen desaturation (below 85\%). Bagmask ventilation was initiated. After there was a response to this, abdominal distension was observed and the colonoscope was withdrawn.

After flumazenil reversal, the patient recovered consciousness and complained of abdominal pain. Radiology revealed free subphrenic air ( $\bullet$ Figure 1). At laparotomy there was no sign of colon perforation, but a $5-\mathrm{cm}$ full-thickness tear was identified at the gastric corpus. A twolayer gastric closure was undertaken, and at the end of the operation the patient was sent to the intensive care unit.

After $48 \mathrm{~h}$, heart failure and pulmonary congestion were diagnosed. The patient had respiratory failure on the fourth postoperative day and required mechanical ventilation. Cardiac arrhythmia preceded cardiogenic shock. The patient died on the 10th postoperative day, due to circulatory failure.

The purpose of sedation and analgesia is to relieve anxiety and pain and to diminish memory [1]. Oxygen administration reduces oxygen desaturation during endoscopy [2,3], and oxygen was delivered using a nasopharyngeal catheter $35 \mathrm{~cm}$ in length.

The finding of a tear in the center of a serosal tear in the stomach ( $\bullet$ Figure 2 ) was not associated with adhesions. The patient had not vomited and no nasogastric tube was used. The serosal tear indicated a pneumatic origin. An over-inserted and misplaced nasopharyngeal catheter (๑ Figure 3) with a $4 \mathrm{~L} / \mathrm{min}$ oxygen flow into the stomach could have been the cause [4-6], and must also have been the reason for the hypoxemia in the first place. The use of a twin-prong nasal oxygen set would have prevented this rare complication.

Endoscopy_UCTN_Code_CPL_1AJ_2AB 


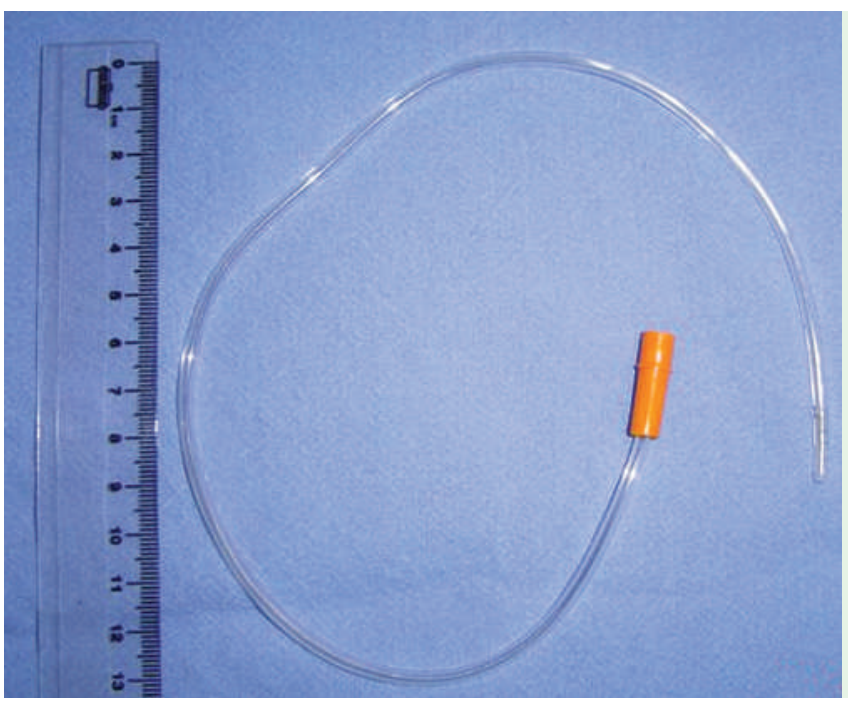

Figure 3 The nasopharyngeal catheter that was used during the procedure.

\section{S. E. A. Araujo, R. Degrandi,} J. A. C. Martins

Santa Casa Hospital, Santos, Sao Paulo State, Brazil

\section{References}

1 Faigel DO, Baron TH, Goldstein JL et al: Guidelines for the use of deep sedation and anesthesia for GI endoscopy. Gastrointest Endosc 2002; 56: 613-617

2 Bell GD, Bown S, Morden A et al: Prevention of hypoxaemia during upper-gastrointestinal endoscopy by means of oxygen via nasal cannulae. Lancet 1987; 1: 1022 - 1024

3 Griffin SM, Chung SC, Leung JW, Li AK: Effect of intranasal oxygen on hypoxia and tachycardia during endoscopic cholangiopancreatography. BMJ 1990; 300: 83-84

4 Song JK, Stern EJ, Beaty CD: Gastric perforation: a complication of inadvertent esophageal intubation. AJR Am J Roentgenol 1995; 164: 1386

5 Low LL, Ripple GR, Bruderer BP, Harrington $G R$ : Non-operative management of gastric perforation secondary to cardiopulmonary resuscitation. Intensive Care Med 1994; 20 : $442-443$

6 Reiger J, Eritscher C, Laubreiter K et al: Gastric rupture - an uncommon complication after successful cardiopulmonary resuscitation: report of two cases. Resuscitation 1997; 35: $175-178$
Bibliography

DOI $10.1055 / \mathrm{s}-2006-945103$

Endoscopy 2007; 39: E75-E76

(c) Georg Thieme Verlag KG Stuttgart · New York . ISSN 0013-726X

\section{Corresponding author}

\section{S. E. A. Araujo, MD}

Santa Casa Hospital

Cristiano Viana 450 ap. 62

05411-000

Sao Paulo, SP

Brazil

Fax: +55-11-30827748

sergioed@terra.com.br 